\title{
Economic Analysis of Water Infrastructure: Have We Got It Right?
}

\author{
Bhadranie Thoradeniya, Malik Ranasinghe, N T S Wijesekara
}

\begin{abstract}
The paper describes shortcomings of the general economic analysis procedure adopted in water infrastructure development projects in Sri Lanka. As a case study an application of the 'Educated Trade-off' framework in the Ma Oya river basin is used to illustrate the shortcomings of general economic analysis procedure. This framework facilitates the systematic identification of resource uses and the possible range of environmental and social impacts by the water infrastructure project, through the involvement (consultation and participation) of key stakeholders. The study revealed two types of shortcomings that result in erroneous economic indicators: first, the lack of a competent process to establish the baseline situation leading to non-inclusion of some important social and environmental impacts, both positive and negative, by the project and, second, deviations from reasonable practices either due to negligence or on purposes that give decision makers optimistic data which could result in questionable decisions.
\end{abstract}

Keywords: economic analysis, water infrastructure development projects, educated trade-off, stakeholder consultation, natural resources

\section{Introduction}

Water infrastructure development can be considered as a production process as the purpose of production is to convert a set of inputs (e.g. river flow, concrete, steel and other building materials) to a set of outputs (e.g. irrigation, water supply, and hydropower generation projects). This justifies the application of production functions, cost benefit analysis and other economic analysis to water resource infrastructure development [20].

In the economic analysis of an infrastructure project, the total value of the resource has to be considered to maximise the efficiency. The total value of a resource consists of its use and nonuse values. The basic measures of use and nonuse values are maximum willingness to pay (WTP) to prevent environmental damage or realise an economic-environmental benefit; and/or minimum willingness to accept (WTA) compensation for accepting a specific degradation in environmental quality [1].

Non-availability of a systematic approach to establish the baseline situation of the full range of use and non-use values of the resources is a key deficiency associated with the procedure generally adopted for economic analysis of water infrastructure projects especially in river development work. Inadequate efforts to include the values of full range of social and environmental impacts due to the development project aggravate the situation. This practice could be due to lack of knowledge, negligence or on purpose.

The objective of this paper is to present a case study on proposed Yatimahana multi-purpose balancing reservoir which is a water infrastructure project on Ma Oya in order to:

a) highlight deviations in economic analysis from reasonable practices either due to negligence or on purpose, and

b) address the above deficiencies through the application of an 'Educated Trade-offs' framework [16], [17].

The 'Educated Trade-offs' framework developed by Thoradeniya [17] is a decisionmaking tool to facilitate trade-offs between different resource uses by educating the stakeholders on the combined economic value (economic estimates and environmental and social costs) of each resource use sector.

Eng. Dr. (Mrs.) Bhadranie Thoradeniya, AMIE(Sri Lanka), PhD, Head, Division of Civil EngineeringTechnology,

Institute of Technology, University of Moratuwa

Eng. (Prof.) Malik Ranasinghe, B.Sc. Eng. Hons, Int. PEng.,

C.Eng., FIE(Sri Lanka), M.A.Sc., PhD, Professor in Civil

Engineering and the Vice-Chancellor of the University of

Moratuwa

Eng. (Prof.) N.T.S. Wijesekera, B.Sc. Eng. (Hons), C.Eng.,

FIE(Sri Lanka), MICE(UK), PG. Dip., M.Eng., D.Eng.,

Senior Professor in Civil Engineering, University of

Moratuwa. 
The framework consists of five steps. The first step identifies the stakeholders and the uses/issues of the natural resources in the total area impacted by the project, through the systematic consultation of stakeholder groups. The critical bounds of the technical requirements of the resource uses and issues identified in step one are then estimated in step two. The economic value and the environmental (including social) costs of the respective critical bound of the technical requirements are estimated in the third and the fourth steps. The fifth step combines the economic estimates and the environmental and social costs of critical bounds, to form the basis for 'Educated Trade-offs' for stakeholder consultations [16], [17].

This paper describes the application of the step 1 of the above framework briefly and steps 3 and 4 in detail, which are relevant to the objectives of this paper. The case study application highlighted two main factors; a) the erroneous approaches in the methodologies employed by the project analysts in performing economic analysis of the water infrastructure project b) the inability of general approaches to capture ground realities in the economic analysis. Both the above factors resulted in obtaining wrong economic indicators that would mislead the decision makers.

The next section presents an overview of the economic theories that are used for these analyses. The third section describes the case study (the proposed Yatimahana reservoir) and the baseline scenario. The fourth section presents estimates of combined economic values of the water infrastructure project. The conclusions are given in the fifth section.

\section{Overview of the Economic Theories}

\subsection{Economic Indicators}

Economic Net Present Value (EcoNPV) and Economic Internal Rate of Return (EIRR) analyses are frequently used to determine the difference in economic benefits and economic costs of a water infrastructure project.

The Present Value (PV) of net benefits and costs over time is its value today, usually represented as time zero in a cash flow diagram. In other words, it is the value obtained by discounting the benefits and costs separately for each year over time at a constant discount rate and, throughout the assumed life of a development project [11]. Then, the fundamental relationship to determine the Economic Net Present Value $(E c o N P V)$ of a resource use can be expressed as;

$$
E c o N P V=\sum_{i=0}^{n} \frac{B_{i}-C_{i}}{(1+r)^{i}}
$$

Where $B_{i}$ is the annual economic benefits from the use of resource at the $i^{\text {th }}$ year and $C_{i}$ is the economic cost of the resource use at the $i^{\text {th }}$ year. ' $n$ ' is the duration of the study period and ' $r$ ' is the discount rate [17].

Economic Internal Rate of Return (EIRR) is the most often cited method for comparing alternatives in development projects. The EIRR analysis calculates the return from the development project as a non-dimensional measure. Present value formulations are the foundations for EIRR calculation as the EIRR is calculated by equating EcoNPV given in equation 2.1 to zero and solving for the discount rate that allows the equality [11]. Therefore, Internal Rate of Return (IRR) is generally defined as the rate at which PV of costs is equal to the PV of benefits, or the rate at which the NPV is equal to zero.

The IRR preference (ranking) for an alternative always agrees with that of the NPV preference for projects, which are economically independent of one another (i.e. the selection of a particular project does not preclude the choice of the other). When the alternatives are mutually exclusive, there can be reversal of rankings.

Alternatives are mutually exclusive when the selection of one alternative eliminates the opportunity to invest in any of the others. Most problems in development projects normally fit into this category because a single course of action is sought to solve a particular, often urgent, problem. When the best alternative is determined, the problem is theoretically resolved by implementing the indicated course of action [13].

In choosing between alternatives (i.e. different resource uses), the criterion is to select the one that maximizes EcoNPV. For instance, an EcoNPV of Rs. $Z$ means that the PV of the alternative (resource use) is Rs. $Z$ greater than on an investment of similar size that produces a rate of return equal to the discount rate or the Minimum Acceptable Rate of Return (MARR). 
A negative PV means that the alternative does not satisfy the rate of return requirement, as $M A R R$ reflects the opportunity cost of capital. In other words, the possible return the economy would obtain is lower on the same amount of capital than if invested elsewhere at $M A R R$, assuming that the risks are similar for both investment alternatives $[11,12]$.

\subsection{Financial Analysis}

The starting point of an economic analysis of a resource use is the financial analysis of that resource use. The financial analysis measures the receipts (benefits) and payments (costs) relevant to the investors or owners of the resource/project. It is a tool that provides investors with the information required to decide whether to undertake an investment. Hence, the objectives of the financial analysis are to determine, analyse and interpret all financial consequences that may be relevant to and significant for investment and financing decisions [11].

The financial analysis of a resource use/project is typically carried out at market prices prevailing at the time of the analysis [7]. The estimates for costs and benefits (receipts) are therefore in terms of prevailing market prices. Taxes and subsidies (transfer payments), foreign exchange distortions, monopoly rents, and externalities influence market prices. Market distortions cause market prices to diverge from economic prices [7].

\subsection{Economic Analysis}

According to Jenkins and Harberger [7], for inputs, market prices would reveal the productive value of an item in its next best use. The market prices of an output would signal the level at which the consumer's marginal WTP for an item just equals the cost of producing that item (marginal cost). Instead, market distortions cause market prices to diverge from "economic prices." For example, taxes increase prices and reduce demand. The effect of subsidies is opposite [7], [2].

The financial analysis relies on cash flow techniques to compare and analyse the estimated receipts (benefits) and costs. An economic analysis is of exactly the same nature as a financial analysis, except in the case of an economic analysis, the benefits and costs are measured from the point of view of the economy [7]. Instead of relying solely on cash flow techniques to measure benefits and costs as in the case of the financial analysis, economic valuation requires the use of economic techniques of measurement.

Then, the merit of a resource use is assessed with regard to the impact that use has on the efficiency of the economy as a whole [7]. The market prices are adjusted to reflect the opportunity cost (or shadow price) of goods and services. Then, the cost to society of the project is measured in terms of forgone marginal products of inputs, had they been used in the next best alternative to the resource use. The outputs of the resource use are valued based on their demand price in the absence of market distortions [7].

Ideally, the price of every input and output should be adjusted so that "shadow prices" can be approximated. Once the shadow (economic) price is known, a conversion factor of the ratio of the economic price to the market price, is used to facilitate this adjustment. When the conversion factors are approximated, computer spreadsheet programs easily facilitate the transformation of the financial analysis to the economic analysis. Instead of replacing all financial values with economic values, financial values can be multiplied by the conversion factors to yield economic values [11], [4]. The complexity of finding the economic price depends on the nature of the good or service being considered.

The third step of the 'Educated Trade-off' framework uses these reasoning to estimate the economic value of the water infrastructure project.

\subsection{Extended Economic Analysis}

A negative outcome often linked with the water resources development is the environmental degradation that occurs due to the economic activities [10]. Inclusion of such costs (and benefits) in the water infrastructure project is the basis for the 'Extended Economic Analysis.'

It is imperative to value such impacts to the environment in related decision making [8], [9], [6]. Birol et al. [3] defines the role of economic valuation techniques in the design of efficient, equitable and sustainable policies for water resources management in the face of environmental problems. 
The net environmental cost of a project is the difference between the environmental (including social) benefits and the social and environmental costs of the other uses due to that project. It must be noted that net social and environmental costs referred to here are those, which are either not quantified or underestimated, in the economic analysis. The fourth step uses these reasonings to estimate the environmental and social costs of the water infrastructure project.

The fifth step of the 'Educated Trade-off' framework estimates the combined value of the water infrastructure project. This in fact is the net present value of a scenario obtained by performing the extended economic analysis.

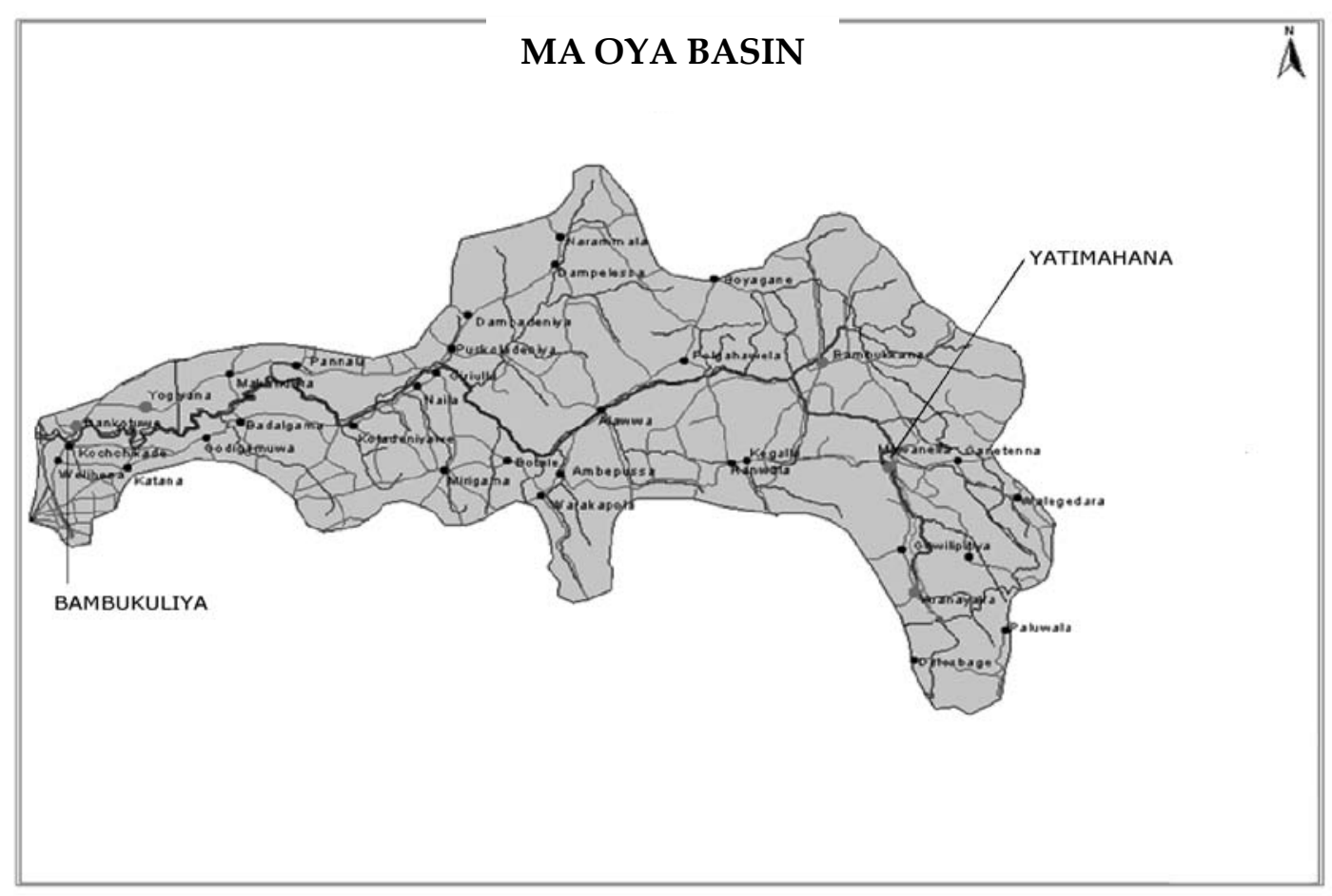

Figure 1 - Ma Oya river basin

\section{Case Study: Yatimahana Multi- purpose Balancing Reservoir Project}

\subsection{River Basin}

Ma Oya river commences in the central hilly regions and flows to the Indian Ocean through north western Sri Lanka. The river drains a catchment area of $1528 \mathrm{~km}^{2}$ along its total length of $130 \mathrm{~km}$ [5]. (See Figure 1).

The river flows are mainly used for supplying drinking water to 17 major population centers, two major industrial zones and also some private water supply schemes. The next major use of the river flow is as a pollutant carrier (absorber) from a number of cities as well as private dwellings located on the riverbanks and from a number of industries located in the river valley.
Highly stressed surface water resource situations are experienced during the 6-8 weeks of the dry season [5]. Thus during the low flow periods the two major uses (water supply and pollutant carrier) are conflicting with each other and results in critical water stressed situation both due to inadequate quantity and poor quality [5], [19].

The NWSDB, a key stakeholder of the river basin has proposed a multi-purpose balancing reservoir in the upper catchment at Yatimahana (See Figure 1) as the best option in an attempt to mitigate the expected severe water shortages in the near future due to the increasing demands, [15].

The objective of this reservoir project is to store the excess flows of the river during rainy seasons and then to release the required flows, under control, during the dry weather periods. The proposal acknowledges the importance of Integrated Water Resources Management 
(IWRM) and has considered irrigation, industry and hydropower sectors in addition to the water supply and sanitation sector. Hydropower is proposed mainly as a strategy for achieving the economic viability of the reservoir project [15].

\subsection{Baseline Scenario}

The resource uses and issues of a river show a significant variation spatially and temporally. It is therefore vital to establish the baseline situation and the possible impacts by the water infrastructure project prior to engaging in economic analyses. The baseline situation should be established by carrying out systematic surveys covering the entire area that is expected to be impacted by the project.

A main feature of the 'Educated Trade-off' framework is the establishment of the baseline scenario with regard to total value of the resource against the current practice of limiting the analyses mostly to direct use values.

The first step of the 'Educated Trade-off' framework is developed on the premise that the establishment of the most accurate baseline situation for identifying the resource uses is through the bottom level (grass-root) stakeholder consultations. The methodology used for the identification of stakeholders and issues was to conduct sample surveys along the river banks at the smallest administrative unit (Grama Niladhari Division - GND) level.

In this case study, the sample constituted of 427 stakeholders from 145 GNDs along both river banks from river estuary to Aranayake (a location upstream of the proposed reservoir), representing all sectors having a stake in the river including public administration, public and private institutions in river resource use sectors. It also included representatives of social, political, religious, and ethnic groups of public at grass-root level. A detailed analysis of the data collected through the sample survey is presented by Thoradeniya [17], and Thoradeniya and Ranasinghe [18], with regard to the resource uses and stakeholders.

The major resource use sectors, which could be significantly impacted by the proposed water infrastructure project, were identified in two groups. First are the sectors which are spatially widespread such as, water supply schemes, industries using river water, dug-wells, rainfed agriculture and industrial waste disposal sectors. Second are the other use sectors, which are more localised in nature; such as recreation and tourism.

Use sectors like hydropower, tourism, sand and clay mining have created localised adverse impacts to the environment and local populations. Already documented environmental and social impacts by the different use sectors range from drying up of springs used for drinking and household needs of the villagers at upstream locations to dried up well and abandoned paddy lands [12], [19].

An interesting finding of the baseline scenario was the current situation of the irrigation sector. The project economic analysis considered three irrigation projects down stream of the Yatimahana reservoir as contributing economically. However, Yaka Bendi Ela scheme is still a proposal while the other two, Pannala and Makandura lift irrigation schemes are abandoned. The economic analysis assumed an annual income of Rs. 100,000,000 from these three irrigation schemes.

The stakeholder consultations at grass-root level revealed that the real reason for abandoning the two lift irrigation schemes was not the inadequacy of water but the inability of farmers to meet the cost of energy for lifting water. More interestingly it was found that parts of land under these schemes have been reallocated under the political visions of the area for other purposes such as housing making it difficult to rehabilitate the schemes. Therefore, the assumed irrigable area under the three schemes of 453 ha., is in reality a fantasy.

Another finding was the inadequacy of the present head works, which are in a dilapidated condition, for lift operations as the river water level has dropped by about $5-6 \mathrm{~m}$ since the time these schemes were abandoned.

\section{Economic analysis of the Yatimahana project}

\subsection{Feasibility Study}

The project feasibility study [15] identified economic benefits of the project from power generation, increased water sales, crop production, land value increases and generations of new business activities (Table 1). 
Table 1 - Project Benefits (in Rs. Millions)

\begin{tabular}{|c|c|c|c|c|c|}
\hline むี & 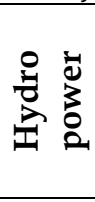 & 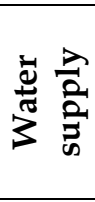 & 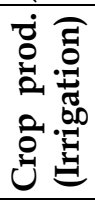 & 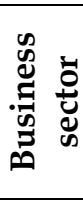 & 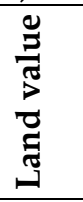 \\
\hline 1 & 230 & 0 & 100 & 130 & 120 \\
\hline 2 & 114 & 4 & 100 & 130 & - \\
\hline 3 & 101 & 28 & 100 & 130 & - \\
\hline 4 & 146 & 42 & 100 & 130 & - \\
\hline 5 & 192 & 2 & 100 & 130 & - \\
\hline 6 & 103 & 43 & 100 & 130 & - \\
\hline 7 & 75 & 73 & 100 & 130 & - \\
\hline 8 & 149 & 22 & 100 & 130 & - \\
\hline 9 & 141 & 17 & 100 & 130 & - \\
\hline 10 & 145 & 18 & 100 & 130 & - \\
\hline 11 & 163 & 3 & 100 & 130 & - \\
\hline 12 & 228 & 0 & 100 & 130 & - \\
\hline 13 & 196 & 1 & 100 & 130 & - \\
\hline 14 & 187 & 0.5 & 100 & 130 & - \\
\hline 15 & 182 & 3 & 100 & 130 & - \\
\hline 16 & 88 & 13 & 100 & 130 & - \\
\hline 17 & 22 & 37 & 100 & 130 & - \\
\hline 18 & 98 & 21 & 100 & 130 & - \\
\hline 19 & 134 & 15 & 100 & 130 & - \\
\hline 20 & 80 & 15 & 100 & 130 & - \\
\hline
\end{tabular}

(Source: SWECO GRØNER, 2004)

The economic costs of the project were due to capital costs, which include construction costs of the dam and the powerhouse, refurbishment cost of electrical and mechanical components and land acquisition costs and recurrent costs (Table 2).

Table 2 - Project Costs (in Rs. Millions)

\begin{tabular}{|c|l|c|}
\hline Year & \multicolumn{1}{|c|}{ Item } & $\begin{array}{c}\text { Estimated } \\
\text { Cost }\end{array}$ \\
\hline-2 & $\begin{array}{l}\text { Capital costs, } \\
\text { operation and } \\
\text { maintenance costs, } \\
\text { resettlement costs and } \\
\text { compensation costs. }\end{array}$ & 1,352 \\
\cline { 3 - 3 } & Rehabilitation cost & 33 \\
\hline 10 & $\begin{array}{l}\text { Annual operation and } \\
\text { maintenance }\end{array}$ & 9 \\
\hline
\end{tabular}

(Source: SWECO GRØNER, 2004)

(Note: In Table 2, Year - 2 and - 1 indicates the time before the project implementation or the construction period).

The economic analysis of the benefits and costs yielded an EIRR of $15.2 \%$ considering a project life of 20 years [15].

The above analysis consisted of following three deviations from the normal practice $(\mathrm{a}, \mathrm{b}$ and $\mathrm{c}$ ) and two key deficiencies (d and e) from the reasonable economic analysis for such water infrastructure projects:

a) Placement of costs and benefits on time axis of cash flow diagram.

The reasonable approach to perform economic analysis for an infrastructure development project is to consider the operation and maintenance costs $\left(\mathrm{C}_{\mathrm{i}-1}, \mathrm{C}_{\mathrm{i}}\right.$, $\mathrm{C}_{\mathrm{i}+1}$ ) that would incur during a specified time unit (usually 1 year) at the beginning of the period and the benefits $\left(R_{i-1}, R_{i}, R_{i+1}\right)$ at end of the period (Figure 2).

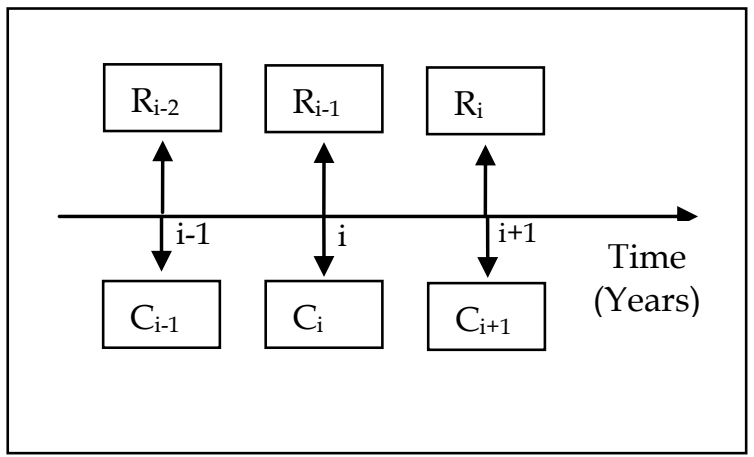

Figure 2 - Reasonable approach for costs and benefits in the cash flow diagram

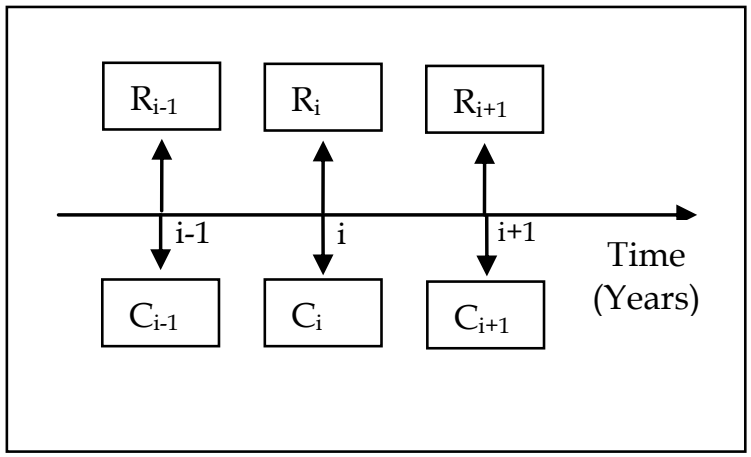

Figure 3 - Approach used by the project consultants for costs and benefits in the cash flow diagram

Even though, reality would be to consider costs and benefits as they occur in time, the above process provides a reasonable approximation. However, in the economic analysis by the project consultants [15], both costs and benefits for a single duration have been considered at the end of the discounting period (Figure 3). This is a common mistake that happens when computer packages are used to estimate the IRR, which yields an optimistic estimate. 


\section{b) Use of annual tariff increments}

The economic analysis should be on constant values of the year on which the analysis is done. This is to overcome any over/under estimation of benefits for one alternative against another. Then, the comparison between alternatives or "go or no-go" decision is based on constant values.

In the study by the consultants [15], water supply sector annual financial income was estimated on the assumption that $80 \%$ of the water is sold for domestic purposes and the balance $20 \%$ is sold for commercial purposes.

The tariffs for the first year had been taken as the constant (2004) tariffs, which were Rs. 2.90 and Rs. 42.00 for the domestic and commercial sectors, respectively. Thereafter annual tariff increases of $20 \%$ and $16 \%$ had been used for the domestic and commercial sectors claiming that these assumptions are based on past experience. This yielded a significant overestimation of the benefits.

The tariff used for electricity sales is based on the 2004 rates used by the Ceylon Electricity Board in purchasing bulk supplies from private sector. The rate applied during the lean period of the year (February, March and April) is Rs. 5.70 per kwh while a rate of Rs. 4.95 is applied during the rest of the period considering it to be the wet period. In the analysis these basic rates were then increased by $10 \%$ per year for annual price escalations, which again resulted in overestimation of benefits.

\section{c) Project life}

The project life of civil structures such as dams is usually taken as 50 years for economic analysis. The cost incurred by such massive structures cannot be recovered during 20 years, which is a relatively short period. Since the selection of project life has been organisation dependent rather than the project and its components, there is an underestimation of benefits.

d) Inadequate effort to include the values of full range of social and environmental impacts.
The economic analysis has not captured important environmental (including social) costs (or benefits) due to the project impacts. A key cost that has been missed was from recreation sector while key benefits from tourism and industrial sectors have also been missed. In addition, a key benefit that is missed is the avoided social and environmental costs by the beneficiaries of the future water supply schemes as a result of Yatimahana reservoir.

e) Lack of a systematic approach to establish the baseline situation

In estimating the economic benefits from the irrigation sector, the economic analysis for example does not provide for the cost of new infrastructure required for the rehabilitation of existing schemes and the construction of the new schemes as discussed in section 4 . Thus, lack of a systematic approach to establish the baseline situation has led to the total income from crop production to be considered as a benefit for the Yatimahana reservoir project when in reality there was no reported water deficiency for the irrigation sector.

There is a dilemma on the acceptable value of EIRR. One school of thought is that EIRR for public utility projects could be very low (even negative). The underlying argument is that such projects have an immeasurable social value (benefit) to the public over time [14]. An attempt to value the cost of alternative source of water for project beneficiaries (e.g. use of bottled water for drinking) could have captured at least part of this benefit.

\subsection{Improved Analysis}

The application of the third, fourth and fifth steps of the 'Educated Trade-off' framework developed by Thoradeniya [17] to the case study rectified all of the above deviations and deficiencies except one: the avoided social and environmental costs by the beneficiaries of the future water supply schemes as a result of Yatimahana reservoir. This was because of nonavailability of data of all the water supply schemes that would be enhanced by 'Yatimahana' project and lack of time and resources to carry out such a study.

The normal approach that should be used for costs and benefits in cash flow diagram as explained in Figures 2 and 3, brought the EIRR 
down by $2 \%$ from $15.2 \%$ to $13.2 \%$. Once the corrections were applied for undue annual tariff escalations, the EIRR became $8.29 \%$ for a project life of 20 years (see Table 3 ).

Table 3 - Economic Indicators

\begin{tabular}{cccccc}
\hline I\% & EcoNPV & B/C & $\begin{array}{l}\text { PV } \\
\text { Envio } \\
\text { Benefit }\end{array}$ & $\begin{array}{l}\text { Comb } \\
\text { NPV }\end{array}$ & B/C \\
\hline 10 & $-412,627$ & 0.871 & $+12,946$ & $-399,680$ & 0.875 \\
8.34 & $-15,003$ & 0.995 & $+15,003$ & 0 & 1.0 \\
$\mathbf{8 . 2 9}$ & 0 & 1.0 & $+17,695$ & +17695 & 1.004 \\
\hline
\end{tabular}

An attempt was made to use longer durations for project life considering the fact that the major cost component of the project was for civil constructions such as the dam, which has a life span more than 20 years. A forty year life span with additional refurbishment costs for electrical and mechanical components at 10 year interval increased the EIRR by $2.34 \%$.

Stakeholder consultation survey carried out in step-1 of the 'Educated trade-off framework', contributed in two ways: First, the stakeholder consultations revealed the ground reality regarding the irrigation sector as discussed in section 4. Accordingly, the removal of irrigation benefits brought the EIRR down by $3.79 \%$ to an estimated value of $4.5 \%$ for the EIRR.

Second, it identified stakeholder concerns in five use sectors which were expected to be impacted by the project; Recreation sector, Rain fed agriculture, Dug-well sector, Industry uses and Tourism sector. Detailed studies on these sectors concluded as follows [17]:

i. In the recreation sector the annual loss by the inundation of a water fall by the proposed reservoir is estimated as Rs. 1.2 million per annum.

ii. The impacts to the rain-fed agriculture and the dug-wells depend on the variation of river water levels during the dry season which in turn affects the ground water level in the vicinity. The analysis in the step- 2 of the framework indicated the variations to the river water levels in the down stream areas in the dry season due to the project has a marginal positive impact which is insignificant to be estimated in economic terms.

iii. The industries are expected to benefit by the flood mitigation effect of the proposed reservoir due to the reduction of turbid water. This positive impact is valued at Rs. 0.45 million per annum.

iv. The upper river bank houses a tourist attraction where an elephant orphanage is operated at Pinnawala. The high flows (floods) do not permit the elephants to use the river for bathing due to the possibility of small elephants being washed away. In this instance the impacted sector are the business enterprises which cater to the tourists and situated along the route taken by the elephants from the orphanage to the river and not the orphanage itself. The benefit by the proposed balancing reservoir due to reduced flood days to the tourism sector is estimated at Rs. 2.59 million per annum.

The total Environment (including social) benefits of the project is therefore Rs. 1.84 millions per annum which raise the EIRR by $0.05 \%$.

The fifth step of the 'Educated Trade-off' framework facilitated the estimation of a combined value for the project scenario by adding the economic value and the environmental costs (e.g. Combined NPV for the project after corrections discussed under (a), (b) and (d) was Rs. - 399,681 with an EIRR of $8.34 \%$. See Table 1). Further, analysis indicated that an additional annual benefit of Rs. 48.3 million over 20 years would bring the project EIRR to the MARR of $10 \%$.

An important benefit that could have contributed to the proposed project at the fourth step of the framework is the avoided social and environmental cost to the people who would be supplied with water under the proposed reservoir project. The estimate of these benefits were not possible at the time of the study as the project reports of all the water supply schemes that would be enhanced by 'Yatimahana' project were not available. However, this is an important benefit that water infrastructure projects especially in the water supply sector should estimate.

\section{Conclusions}

The economic analysis of the proposed Yatimahana project on the Ma Oya basin highlighted deviations and deficiencies from the reasonable procedures for economic analysis due to lack of knowledge, negligence or on purpose.

The application of the 'Educated Trade-off' framework enabled identifying the baseline situation and performing the extended economic analysis with the inclusion of values 
of a range of possible environmental (including social) impacts from the Yatimahana project.

From the experience gained in the case study the following conclusions with regard to the economic analysis of water infrastructure projects can be drawn.

a) The timing of costs and benefits should be properly used for the economic analysis when computer packages are used to estimate the IRR.

b) Economic analysis should be on constant values. Unreasonable escalations of annual tariff over estimates the decision parameters, and gives optimistic results for decision makers.

c) Use of the 'Educated Trade-off' framework [17] in water infrastructure development projects is recommended for its multiple advantages. In an economic analysis it facilitates the establishment of baseline situation and identifies the use sectors that could be impacted by the proposed project.

d) The economic analyses should include the avoided social and environmental costs to people who would be benefitted by the water infrastructure development project.

\section{Acknowledgement}

This research study was carried out with a grant from the International Development Research Centre, Ottawa, Canada which is gratefully acknowledged.

\section{References}

1. ADB, Economic Evaluation of Environmental Impacts. A Workbook, Asian Development Bank, Manila, Philippines, 1996.

2. Baneth Jean, "Selecting Development Projects for the World Bank," Discussion Paper, 322, World Bank, 1996.

3. Birol Ekin, Katia Ka, Rousakis and Phoebe Koundouri. "Using Economic Valuation Techniques to inform Water Resources Management: A Survey and Critical Appraisal of Available Techniques and an Application," Science of the Total Environment, 2006, Vol. 365, p 105-122.

4. Curry, S. and Lucking, R., "Shadow Prices for Sri Lanka, Sri Lanka", National Planning Department, 1992.
5. DHI, "Working Document A: Maha Oya River Basin, Detailed Basin Assessment", Western River Basin Sector Project TA 3030 - SR ,I Danish Hydraulic Institute, 1999.

6. Emerton, Lucy and Kekulandala, L. D. C. B., "Assessment of the Economic Value of 3.1 River Basin Muthurajawela Wetland", Occasional Papers of IUCN, Sri Lanka, 2003.

7. Jenkins, G. P. and Harberger, A. C., “Manual Cost-Benefit Analysis of Investment Decisions", Harvard Institute for International Development, 1992.

8. Markandya, A. and Richardson, R., "Environmental Economics", London, Earthscan Publications Ltd., 1992.

9. Munasinghe, Mohan and Ernst Lutz. "Environmental-Economic Evaluation of Projects and Policies for Sustainable Development", Environment Working Paper No. 42, World Bank, 1991.

10. Panayotou Theodore., "Green Markets, The Economics of Sustainable Development", A co publication of International Center for Economic Growth and The Harvard Institute for International Development, USA, Institute of Contemporary Studies Press, 1993.

11. Ranasinghe, M., "Risk and Uncertainty Analysis of Natural Environmental Assets Threatened by Hydropower Projects: Case Study from Sri Lanka," Energy for Sustainable Development, 2002, Vol. VI(1), p 56-63.

12. Ranasinghe, M., "Reconciling Private Profitability and Social Costs: The Case of Clay Mining in Sri Lanka", Project Appraisal, Beech Tree Publishing, U.K., Vol. 12, No.1, pp.31-42. 1997.

13. Riggs, J. L., Rentz, W. F. and Khal, A. I., "Essentials of Engineering Economics", Toronto, McGraw-Hill Ryerson Ltd., 1983.

14. Siyambalapitiya, T., "Solace for Land Transportation in Sri Lanka - Railway Electrification and Its Economics", John Diandas Memorial Lecture, Institute of Engineers, Sri Lanka, 2009.

15. SWECO GRØNER, "Improvement of Water Availability for Water Supply Schemes from Maha Oya", final report, Volume I - Main report, 2004.

16. Thoradeniya, B. and Ranasinghe, M., “A Methodology for Effective Stakeholder Participation through Educated Trade-Offs", Transactions of Institution of Engineers Sri Lanka, 2006. 
17. Thoradeniya, B, “Stakeholder Involvement in the Decision Making for Development Projects Using 'Educated Trade-Offs'”, Ph D thesis, 2009.

18. Thoradeniya, B. and Ranasinghe, M., Key note address, International Conference in Building Education and Research, Kandalama, Sri Lanka., 10-15 February, 2008.

19. Thoradeniya, W. B. M., “Evaluation Report on the longest serving Area Water Partnership in Sri Lanka", Lanka Jalani, Colombo, 2005.

20. Vedula, S. and Mujumdar, P. P., "Water Resources Systems, Modeling Techniques and Analysis", New Delhi, Tata McGraw-Hill Publishing Company Limited, 2005. 